\title{
Formation of regional conditions for the development of healthy lifestyle infrastructure using public and private partnership mechanisms
}

\author{
Daria Travnikova, and Elena Dvoryadkina \\ Ural State University of Economics, Yekaterinburg, Russia
}

\begin{abstract}
The article considers the conditions for the formation of a healthy lifestyle infrastructure in the context of the development of the health care system using the foreign practice of public-private partnership. The article also focuses on the imperfection of the existing health care system and the system of ensuring a healthy lifestyle of the population, on the regional specifics that must be taken into account when implementing the state policy in the field of public health protection in a certain territory. A study of the infrastructure of the health care system and the infrastructure of a healthy lifestyle was conducted. The economic and institutional assessment of the activities of health authorities in the context of the use of public-private partnership mechanisms is given. It is noted that the development of the health care system is impossible without the joint efforts of private organizations, central and territorial state authorities. The author's definition of the concept of healthy lifestyle infrastructure is given in the article. Improving the infrastructure of a healthy lifestyle, at the same time, is possible only with the use of public-private partnership (PPP), as a key mechanism for interaction between authorities, legal entities and citizens, especially taking into account the regional and municipal specifics of a certain territory.
\end{abstract}

\section{Introduction}

In the modern economy, the reproduction of the living conditions of society plays a crucial role. It is the creation of socio-economic mechanisms for the development of the family, of each individual person, that is becoming almost a key factor in the growth of public welfare and the development of the national economy. In the context of the Russian President's Address to the Federal Assembly in 2021, the social aspects of economic development were identified as key. In this sense, the development of the regional infrastructure of a healthy lifestyle is becoming the most important direction of changing the social sphere in the subjects of the Russian Federation.

The modern health care system in Russia, on the one hand, is a set of rules, principles and specific measures aimed at ensuring and protecting the health of the population in a certain territory, and, on the other hand, the health care system is a set of organizations that provide health protection activities, medical activities (current, preventive, etc.). Thus, the 
health care system has specifics in specific territorial conditions, i.e. it is adjusted to the needs of the regional community. At the same time, they use statistical data on morbidity, on the current state (constant monitoring) of the health of the population in this particular region. The regional health care system is based on the principles of insurance medicine and the principles laid down by N. A. Semashko [1].

The health care system operates in accordance with the legislation on health protection in the Russian Federation. Article 2 of the Federal Law «On the Basics of Public Health Protection in the Russian Federation» of 21.11.2011 No. 323-FZ states that the issues of regulating activities in the field of public health protection are the subjects of joint jurisdiction of the Russian Federation and the subjects of the Russian Federation (Article 1 of the Law). At the same time, Article 2 notes that the protection of citizens' health is a system of measures of a political, economic, legal, social, scientific, medical, including sanitary and anti-epidemic (preventive) nature, carried out by state authorities of the Russian Federation, state authorities of the subjects of the Russian Federation, local selfgovernment bodies, organizations, their officials and other persons, citizens in order to prevent diseases, preserve and strengthen the physical and mental health of each person, maintaining his long-term active life, providing him with medical care. We believe that this definition of the legislator as a whole is exhaustive [2].

The problems of managing the health care system are associated with the presence of many control centers. First, it is the federal level of management, which determines the general conditions for the functioning of the health system, second, the regional level, which ensures the functioning of the operational (current) activities of public health organizations, and third, it is the level of private health organizations, for which the institutional conditions for the implementation of the first two levels are formed. In addition, there is also military medicine, and a military health care system. Many levels (and until recently there was also a municipal level) create complexity in the management of the health system, because in addition to the above levels, there is also a division by functional areas, in particular, there is sanitary medicine, veterinary medicine, which are closely related to the provision of preventive measures in general in a certain area. For example, it is impossible to consider issues of healthy lifestyle management without taking into account that certain infectious diseases are transmitted from animals, which requires a comprehensive approach to the formation of a healthy lifestyle infrastructure (that is, joint efforts in solving such problems by both veterinary and sanitary doctors).

\section{Materials and Methods}

The main trends that characterize the existing health care system include the processes of its institutional transformations taking into account new forms and conditions of management, the processes of shifting funding from the state level to the level of independent payment for medical services by the population, as well as the development of regional health care systems. «The transfer of competencies and responsibility for the state and development of health care to the subjects of the Russian Federation and municipalities, associated with the growing contradictions between the expenditure obligations of regional and local budgets and their real financial capabilities, together with the sustainable reproduction of the uneven development of health care in the regions of the country» is noted in the dissertation of A.T. Petrova [3], we can agree with this statement, but also note that resources are not always allocated to regional structures in the necessary and sufficient volume.

The analysis of foreign experience of public administration of health systems shows the need to use mechanisms for strategic procurement of medical care, differentiation of patients on the basis of wealth (and not on the basis of social insecurity). It is worth noting 
that the trend in the world is the growth of economic independence of regional medical centers, rather than district and city hospitals, which are often branches or structures of regional centers. At the same time, these centers are often associated with universities, laboratories, medical research centers and technological bases. In addition, it is necessary to ensure the creation of a system of integrated (social, organizational, financial, economic and technological) monitoring of the health system, which has long existed in the North American health system.

An important issue is the relationship between the health care system and the infrastructure of a healthy lifestyle. In our opinion, they are related as a part and a whole, this is, the infrastructure of a healthy lifestyle, it is part of the health system. The task of its development is, first of all, to create a continuously produced program of preventive measures, including anti-alcohol advertising, anti-tobacco advertising, advertising of physical culture and sports, lectures and conversations with schoolchildren and students, education in the field of specific diseases (AIDS, rabies, new coronavirus infection COVID-19), education in the field of vaccination. The material component of the infrastructure of a healthy lifestyle involves the creation of publicly accessible fitness centers, sports grounds and halls, as well as public stadiums; the creation of clinical centers with halls for comprehensive examination of those who wish, while the existing mechanism of medical examination can be used as a basis. An important aspect is the health resort activity, as part of the infrastructure of a healthy lifestyle. Thus, in our opinion, it is possible to build a healthy lifestyle infrastructure according to the following scheme (Fig. $1)$ :

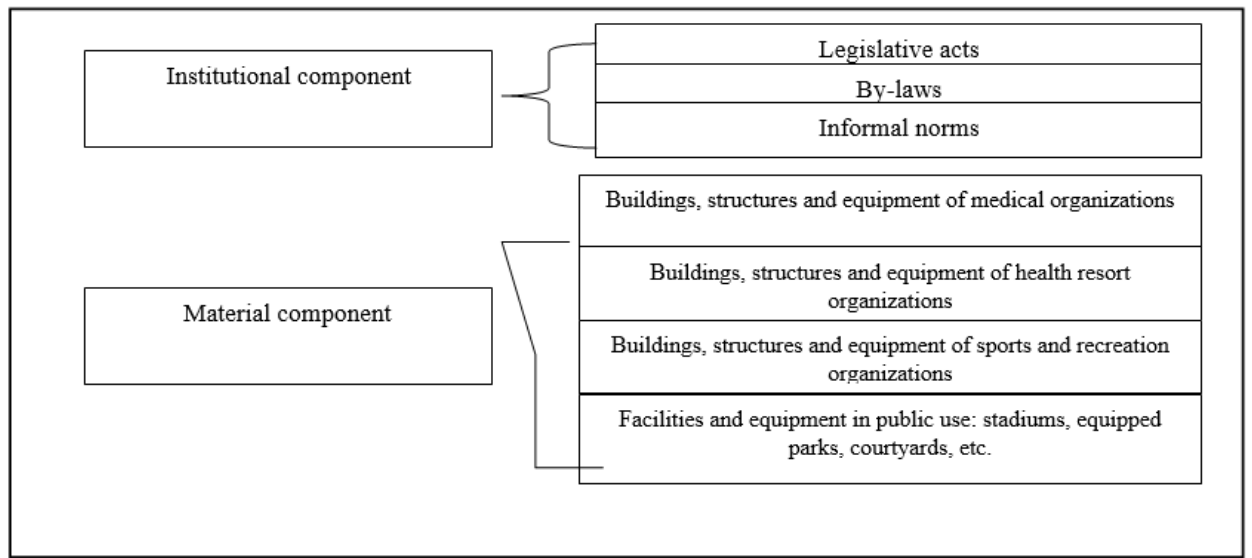

Fig. 1. Healthy lifestyle infrastructure

We will give an assessment of the existing health care system in the Russian Federation [4] in terms of equipment indicators, the availability of medical personnel, the availability of emergency medical care stations. During the formation of the health care system in its modern form, there was a continuous increase in the number of medical personnel, while the number of doctors peaked in 1985-1990, slightly decreased in the 1990s, in the 2000s it again reached the values of the early $90 \mathrm{~s}$. (a deviation of no more than $0,5 \%$ ), which generally indicates the unfairness of the conclusions about the reduction in the number of doctors in the health care system (Fig.2). 


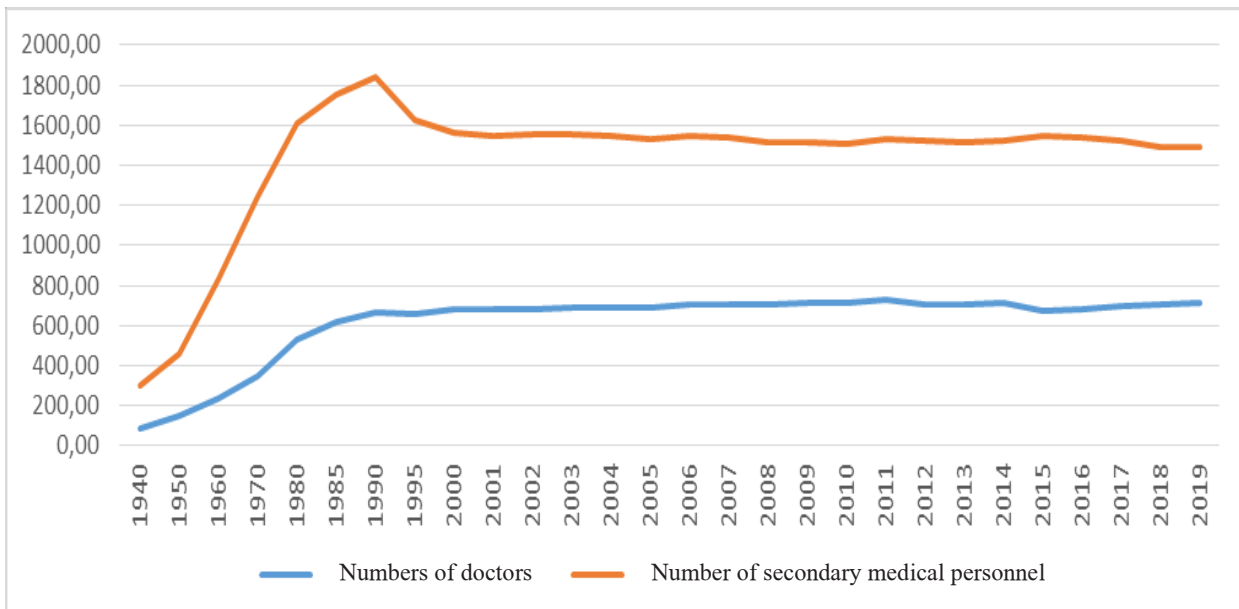

Fig. 2. Dynamics of the number of medical personnel in Russia: number of doctors; number of secondary medical personnel

It is also worth noting that as a key trend in the period from 2005 to 2019 , the growth in the number of polyclinic organizations and the reduction in the number of hospital organizations, while the overall reduction in the number of medical organizations (assuming a relatively small increase in the period 2016-2018), these trends are due to the reform of medical organizations during this period, which is also illustrated in Figure 3:

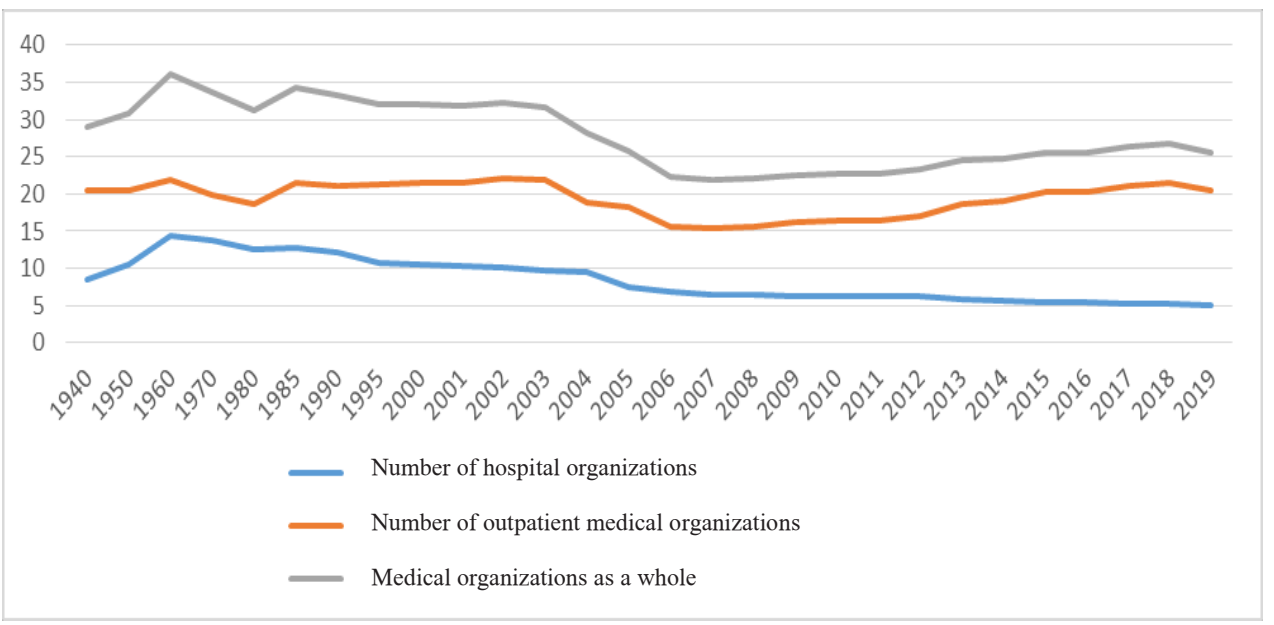

Fig. 3. Dynamics of the number of medical organizations in Russia: number of hospital organizations; number of outpatient medical organizations; medical organizations as a whole

The development of the modern health care system can be assessed as not very positive, since with the overall reduction in the number of medical personnel and the number of medical institutions in the $90 \mathrm{~s}$, this trend continues at the moment, although in a more smoothed form. A common place in the development of the health care system remains the growth of paid medical services and the orientation of sectoral public authorities in the direction of the development of the market for medical services to the population with the strengthening of the role of the private sector. 


\section{Results and Discussion}

In the Russian healthcare system, one of the key issues remains the financing of the activities of healthcare organizations and infrastructure financing, that is, aimed at creating conditions for the functioning of the health care system [5, 6]. Against the background of economic growth, health inequality remains an important problem in all countries and in their regional structures [7].

The authors define the regional infrastructure of a healthy lifestyle as the totality of material and institutional conditions that determine the overall reduction in morbidity in certain territories, increase the effectiveness of preventive measures and provide a general improvement in the quality of life for chronically ill people and the disabled. Therefore, the development of the infrastructure of a healthy lifestyle should be built taking into account industrial and technological, environmental, social and financial and economic factors in a particular subject of the Russian Federation, taking into account the specifics of its municipalities.

For the first time, the concept of PPP was used in the United States in relation to joint programs in the field of education, in these programs the state and private business participated. In the future, the practice of PPP was transferred to the health care system, so the application of such experience in the Russian conditions would be advisable. It is worth noting that in the United States, PPP mechanisms are used everywhere in the public sector of the economy, in particular, joint ventures are created in the municipal sphere, for example, in the housing and communal services. The main conceptual provisions of the PPP theory, based on American practice, were formulated in the 70s and 80s of the 20th century. The American experience and the PPP model were imported to Western European countries during this period.

«Public-private partnership» (PPP) is used as a mechanism for attracting and forming material and financial resources in socially-oriented industries, in which the use of classical indicators of economic efficiency becomes erroneous due to the inability to commercialize certain areas of social activity, for example, hospices or emergency medical care.

In foreign science, this term is used from the point of view of the use of joint resources and, above all, for the purposes of joint attraction and use of investment resources and, hence, the creation of joint structures, for example, most healthcare organizations in the United States are built on the PPP principle. The mechanism of public-private partnership in healthcare is presented in the diagram (Fig. 4): 


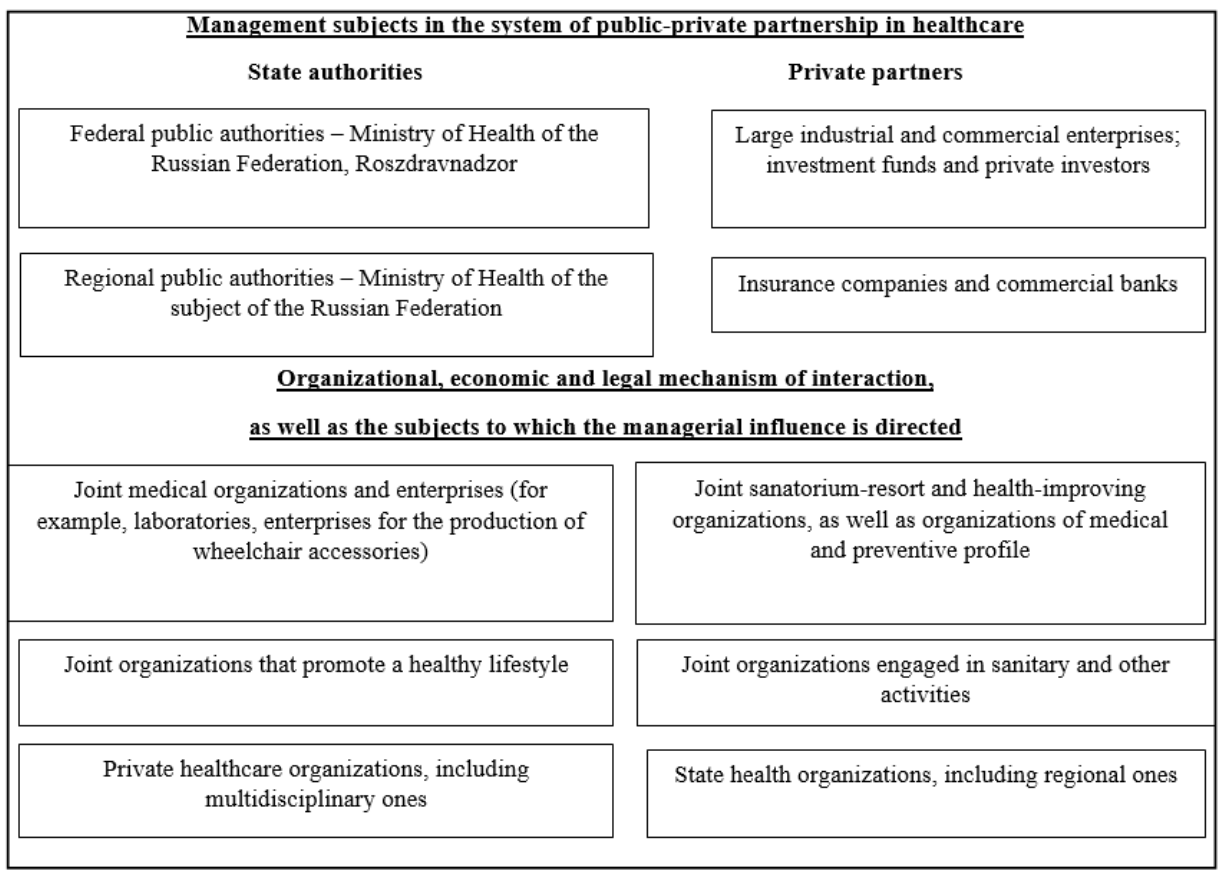

Fig. 4. The PPP system in the field of healthcare and ensuring a healthy lifestyle of the population in Russia

For example, we will consider the implementation of social projects that are related to ensuring a healthy lifestyle in the Sverdlovsk region. These projects were implemented with joint public-private support.

In 2020, 4 socially oriented non-profit organizations that had received state support in the Sverdlovsk Region participated in the implementation of socially significant projects in healthcare in the Sverdlovsk Region. 8 projects were implemented.

The amount of financing was 2980 thousand rubles, including: 1005 thousand rubles at the expense of the federal budget and 1,975.0 thousand rubles at the expense of the regional budget.

The project "Organizing and conducting Dad-Schools" was implemented in the amount of 400 thousand rubles, that was in the direction «Implementation of measures for the prevention of non-communicable diseases, the formation of a healthy lifestyle and sanitary and hygienic education of the population by socially oriented non-profit organizations.»

In the direction «Implementation of measures for the prevention of HIV infection and hepatitis $\mathrm{B}$ and $\mathrm{C}$ to socially oriented non-profit organizations» the amount of funding was 1500 thousand rubles. Three projects have been implemented: support of the volunteer movement «Your life is your responsibility \# get tested for HIV» in the amount of 500 thousand rubles; organization and conduct of «equal» counseling and support for HIVinfected citizens in the amount of 500 thousand rubles; organization of preventive measures for HIV infection among high-risk groups with counseling, rapid testing for HIV infection and social support in the amount of 500 thousand rubles.

In the direction «Promotion of donation of blood and its components by socially oriented non-profit organizations» a project has also been implemented to attract donor volunteers to donate blood and its components in the amount of 45 thousand rubles.

In the direction «Socially oriented non-profit organizations carry out prevention of abandonment of newborn children with developmental disorders» the project «Providing information and psychological support to families in which a child with developmental 
disabilities was born and to families raising children with congenital disabilities» was implemented in the amount of 675 thousand rubles.

In the direction «Support of socially oriented non-profit organizations operating in the field of public health, in the provision of palliative care by medical organizations» a project for the organization and conduct of the School of Palliative Care was implemented in the amount of 270 thousand rubles.

In the direction «Information and consulting support of socially oriented non-profit organizations» a project «Organization of information and consulting support for SONKO of the Sverdlovsk region» was implemented in the amount of 90 thousand rubles.

\section{Conclusion}

Analyzing the current Russian practice in the system of public-private partnership, it is worth mentioning the low efficiency of this mechanism in the social sphere in general and in the health system in particular. So, the existence of a law on PPP does not mean that there are many joint projects in the field of health care, on the contrary, there are very few such projects, and there are no such projects in the Sverdlovsk region at all. In other regions, and in Russia as a whole, the number of such projects does not exceed 30. In general, it is worth noting the unsystematic nature of the reform of the health care system of the Russian Federation, the weak development of program-targeted methods of integrated management, the lack of a single view on the mechanism of preventive measures to promote a healthy lifestyle in the Russian regions. On the other hand, some sources note that risks and instability can become the basis for the development of the health system [8].

The development of the infrastructure of a healthy lifestyle is inextricably linked with the formation of conditions for the development of the health system and, specifically, medical organizations. Therefore, it is necessary to consider the healthcare system in a comprehensive manner, taking into account the territorial conditions that affect the health of the population and the financial and institutional opportunities that modern healthcare organizations in Russia have today.

\section{References}

1. V.A. Reshetnikov, Yu.V. Nesvizhsky, N.A. Kasimovskaya, N.A. Semashko, Journal of the History of Medicine, 3 (2014), https://historymedjournal.com

2. Federal No. 323 "On the Basics of Health Protection of Citizens in the Law of the Russian Federation", Reference and Legal System "Garant", https://base.garant.ru

3. A.T. Petrova, Development of methodological foundations for assessing the quality of life of the population of the region (2008)

4. Rosstat. Healthcare (2019) https://rosstat.gov.ru

5. G.E. Ulumbekova, A.B. Ginoyan, A.V. Kalashnikova, N.V. Alvianskaya, Bulletin of the Higher School of Economics (2019) https://www.vshouz.ru

6. S.V. Dashibylov, Young Scientist, 29 (2020) https://moluch.ru

7. Shambhu Acharya, Sarah-Louise Barber, Daniel Lopez-Acuna, Natela Menabde, Luigi Migliorini, Joaquín Molina, Bernhard Schwartländer, Pascal Zurn, Bulletin of Our Health Organization, 92, 1-6 (2014) http://54.rospotrebnadzor.ru/

8. C. Chamberland-Rowe, F. Chiocchio, I.L. Bourgeault, Healthcare Management Forum, 32, 3, 128 (2019) 